\title{
Guanfacine extended release for children and adolescents with attention-deficit/hyperactivity disorder: efficacy following prior methylphenidate
} treatment

\author{
This article was published in the following Dove Press journal: \\ Neuropsychiatric Disease and Treatment \\ 5 May 2016 \\ Number of times this article has been viewed
}

Michael Huss, ' Vanja Sikirica, ${ }^{2}$ Amaia Hervas, ${ }^{3,4}$ Jeffrey H Newcorn, ${ }^{5}$ Valerie Harpin, ${ }^{6}$ Brigitte Robertson ${ }^{7}$

'Child and Adolescent Psychiatry, Johannes Gutenberg University Mainz, Mainz, Germany; ${ }^{2}$ Global Health Economics, Outcomes Research and Epidemiology, Shire, Wayne, PA, USA; ${ }^{3}$ Child and Adolescent Mental Health Unit, University Hospital Mútua de Terressa, Barcelona, Spain; ${ }^{4}$ Developmental Disorders Unit (UETD), Hospita San Juan de Dios, Barcelona, Spain; ${ }^{5}$ Department of Psychiatry, Icahn School of Medicine at Mount Sinai, New York, NY, USA; 'Ryegate Children's Centre, Sheffield Children's NHS Foundation Trust, Sheffield, UK; ' ${ }^{7}$ Global Clinical Development, Shire, Wayne, PA, USA

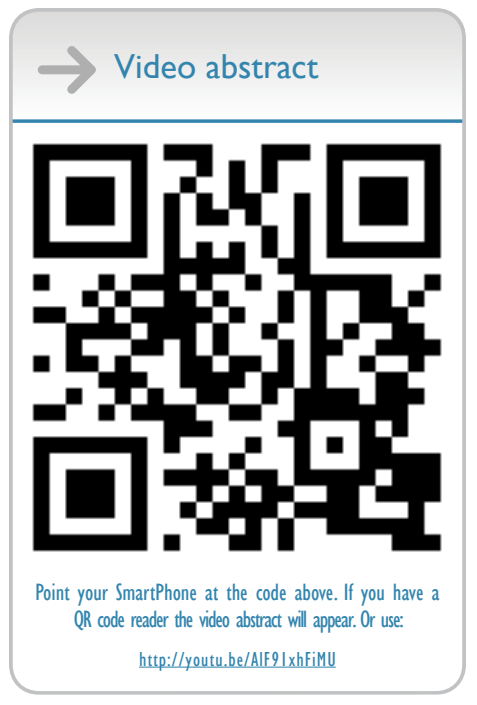

Correspondence: Michael Huss

Child and Adolescent Psychiatry, Johannes Gutenberg University Mainz, Langenbeckstrasse I,

55।3। Mainz, Germany

$\mathrm{Tel}+4961313782300$

Fax +4961313782830

Email m.huss@rfk.landeskrankenhaus.de
Abstract: Guanfacine extended release (GXR) and atomoxetine (ATX) are nonstimulant treatments for attention-deficit/hyperactivity disorder (ADHD). As nonstimulant treatments are often used after stimulants in ADHD, GXR was assessed relative to prior stimulant treatment in a randomized controlled trial (RCT), in which ATX was included as a reference arm, and in the open-label phase of a randomized-withdrawal study (RWS). Participants were 6-17 years old with ADHD Rating Scale version IV (ADHD-RS-IV) scores $\geq 32$ and Clinical Global Impressions - Severity scores $\geq 4$. RCT participants received dose-optimized GXR (1-7 mg/day), ATX (10-100 mg/day), or placebo for 10-13 weeks. RWS participants received dose-optimized GXR (1-7 mg/day) for 13 weeks. Participants' last stimulant medication prior to enrolment, and reasons for stopping this medication, were collected at baseline. Change from baseline ADHD-RS-IV score and the proportion of responders were assessed by prior stimulant exposure. Of 163 RCT and 296 RWS participants who had previously received stimulant treatment, 142 and 224, respectively, had received methylphenidate (MPH); due to the low number of participants and the heterogeneity of non-MPH treatments, we only report data for prior MPH treatment. The most frequent reasons for stopping MPH were lack of effectiveness or side effects. Placebo-adjusted ADHD-RS-IV changes from baseline were significant in participants receiving GXR (prior MPH, $-9.8, P<0.001$, effect size [ES] 0.85; stimulant-naïve, $-7.6, P<0.001$, ES 0.65). In ATX-treated participants, significant placebo-adjusted differences were seen in stimulant-naïve $(-5.0, P=0.022$, ES 0.43$)$ but not prior MPH-treated $(-1.8, P>0.05$, ES 0.15) participants. More participants met responder criteria with GXR versus placebo, regardless of prior treatment. GXR response was unaffected by prior stimulant treatment; ATX produced improvement only in stimulant-naïve participants relative to placebo. These findings may be relevant to clinical decision-making regarding sequencing of ADHD treatments.

Keywords: ADHD, atomoxetine, GXR, inadequate responders, effectiveness, trial

\section{Introduction}

Although stimulant medications, such as methylphenidate (MPH), are the first-line treatment for many individuals with attention-deficit/hyperactivity disorder (ADHD), ${ }^{1,2}$ nonstimulant medications, such as atomoxetine $(\mathrm{ATX})^{3}$ and a prolonged-release formulation of guanfacine (guanfacine extended release [GXR]), ${ }^{4,5}$ provide an alternative option for some patients with ADHD when stimulant treatments are contraindicated or may not otherwise meet their needs. In clinical studies, approximately $30 \%$ of participants have an inadequate response to treatment with a single stimulant. ${ }^{6}$ Factors contributing to an inadequate response include suboptimal inadequate dosing, dose-limiting side effects, 
and poor adherence. Also, patients or their physicians may have a preference for nonstimulant medication.

Guanfacine is a selective $\alpha_{2 \mathrm{~A}}$-adrenergic receptor agonist ${ }^{7,8}$ with documented beneficial effects on prefrontal cortical cognitive functions. ${ }^{9-12}$ Randomized controlled trials (RCTs) in the US have shown GXR to be efficacious and well tolerated as monotherapy or adjunctive therapy for ADHD. ${ }^{4,5,13}$ GXR is approved for the treatment of ADHD as monotherapy or adjunctive to stimulant therapy for children and adolescents (6-17 years) in the US and Canada, and in Europe for children and adolescents (6-17 years) for whom stimulants are not suitable, not tolerated, or have been shown to be ineffective. ${ }^{14}$ ATX is a selective blocker of noradrenaline transporters, ${ }^{15}$ and is approved in the US and several European countries as monotherapy for treatment of children aged 6 years and older, adolescents, and adults with ADHD. ${ }^{16}$

As nonstimulant treatments are often used after stimulants in the treatment of ADHD, it is important to understand how these medications perform following exposure to stimulants. To date, however, there have been limited available data that directly address this question. Findings from a large, placebocontrolled, double-blind study of ATX versus MPH suggested that ATX was less effective in participants previously treated with stimulants than those who were stimulant-naïve. ${ }^{17} \mathrm{~A}$ recent meta-regression analysis supports this finding, in that studies with a greater proportion of treatment-naïve patients were associated with a greater effect size (ES) for ATX compared with placebo. ${ }^{18}$ However, it is unknown whether lesser response following prior stimulant treatment is specific to ATX or would extend to other nonstimulants, such as guanfacine.

Here, we report data from two international Phase III trials on the efficacy of GXR, analyzed according to prior stimulant treatment (prior stimulant treatment or stimulantnaïve). These analyses were prespecified as a separate analysis plan to the main study outcomes. The first study was an RCT that assessed the efficacy and safety of dose-optimized GXR compared with placebo in children/adolescents with ADHD in Europe, the US, and Canada (NCT01244490). ${ }^{19}$ An ATX active reference arm was included to provide benchmark data for an existing nonstimulant treatment. The second Phase III study was a randomized-withdrawal study (RWS) designed to evaluate the long-term (6-month) maintenance of efficacy of GXR in children/adolescents with ADHD in Europe, the US, and Canada who had responded to an initial, short-term (13-week) open-label (OL) treatment phase (NCT01081145). ${ }^{20,21}$ The current analyses utilized data from only the OL phase of the RWS, and were included to provide cross-validation of the effects of GXR in a larger data set than the RCT. The objective of these analyses was to assess whether the effects of nonstimulant treatments were influenced by prior treatment with stimulant medication.

\section{Materials and methods}

The study protocols, protocol amendments, protocol administrative changes, final approved informed consent, assent documents, relevant supporting information, and all types of participant-recruitment information were approved by the study centers' ethics committees and regulatory agencies (as appropriate) prior to study initiation (protocol) or implementation (amendments). The studies were conducted in accordance with International Conference on Harmonisation of Good Clinical Practice, the principles of the Declaration of Helsinki, and other applicable local ethical and legal requirements. Written informed consent was obtained from all participants or their legally authorized representative before the performance of any study-specific procedures.

\section{Participants}

Children and adolescents (6-17 years old) with a diagnosis of ADHD (ADHD Rating Scale version IV [ADHD-RS-IV] total score $\geq 32$ ) of at least moderate severity (Clinical Global Impression - Severity scale [CGI-S] score $\geq 4$ ) were enrolled in both studies. Full inclusion and exclusion criteria have been reported elsewhere. ${ }^{19-21}$ Briefly, participants with age-appropriate intellectual functioning; blood pressure measurements within the 95th percentile for age, sex, and height; and the ability to swallow tablets were eligible to participate. Girls of childbearing potential underwent pregnancy tests at screening and baseline, and had to comply with any protocol contraceptive requirements. Exclusion criteria included clinically significant illness or current, controlled (requiring a prohibited medication or behavior-modification program) or uncontrolled comorbid psychiatric diagnosis (except oppositional defiant disorder); history/presence of cardiac abnormalities (conduction or rhythm abnormalities, bradycardia, exercise-related cardiac events, syncope); orthostatic hypotension or hypertension; seizures; glaucoma; history of alcohol or substance abuse; and serious tic disorder, including Tourette's syndrome. Participants who were currently considered a suicide risk (investigator opinion), had previously made a suicide attempt, or demonstrated prior or current active suicidal ideation were excluded.

\section{Study designs \\ RCT}

The RCT was a double-blind, parallel-group, placebocontrolled study (NCT01244490; EUdraCT 2010-018579-12) 
conducted at 58 centers in Europe, the US, and Canada between January 2011 and May 2013. ${ }^{19}$ Participants were randomized at baseline $(1: 1: 1)$ to treatment with dose-optimized GXR (children [6-12 years], 1-4 mg/day; adolescents [13-17 years], 1-7 mg/day), ATX (10-100 mg/day), or placebo. The total study treatment duration was 10 weeks for children and 13 weeks for adolescents (Figure S1A).

GXR was administered as tablets $(1,2,3$, and $4 \mathrm{mg})$ and ATX as capsules $(10,18,25,40$, and $60 \mathrm{mg})$ in a double-dummy design. Titration of the two drugs has been previously described. ${ }^{19}$ Briefly, GXR dosing was initiated at $1 \mathrm{mg} /$ day and increased by $1 \mathrm{mg}$ increments after a minimum of 1 week to a maximum dose of $4 \mathrm{mg}$ /day in children and 4-7 mg/day in adolescents (optimal GXR dose of $0.05-0.12 \mathrm{mg} / \mathrm{kg} /$ day). ATX dosing was initiated at approximately $0.5 \mathrm{mg} / \mathrm{kg} /$ day in children and adolescents weighing less than $70 \mathrm{~kg}$ at baseline, and increased after a minimum of 1 week to the target of approximately $1.2 \mathrm{mg} / \mathrm{kg} /$ day. If well tolerated, ATX dosing could be further increased to a maximum of $1.4 \mathrm{mg} / \mathrm{kg} / \mathrm{day}$ after at least 1 week. ATX dosing in participants weighing $70 \mathrm{~kg}$ or more at baseline was initiated at $40 \mathrm{mg} /$ day, increased after at least a week to $80 \mathrm{mg} /$ day, and after a further week could be increased to $100 \mathrm{mg} /$ day, if required; this was the total permitted maximum daily dose. ATX was titrated as supported by the prescribing information/summary of product characteristics European label. ${ }^{16}$

Response was defined as a $\geq 30 \%$ reduction in ADHDRS-IV total score from baseline, and a CGI - Improvement (CGI-I) rating of 1 (very much improved) or 2 (much improved) in the absence of safety or tolerability issues. Investigators could titrate to a higher dose if they believed that more beneficial effects could be achieved.

\section{RWS}

The RWS was a multicenter, double-blind, placebo-controlled study. This study started with an OL 7-week dose-optimization period during which participants received GXR (1-7 mg/ day), followed by 6 weeks' OL maintenance of the optimized dose (NCT01081145; EUdraCT 2009-018161-12). ${ }^{20,21}$ After the dose-optimization phase, participants were randomized to continue GXR or to placebo for assessment of maintenance of efficacy, but data from the randomized phase are not included in this analysis. The study was conducted in 67 centers in Europe, the US, and Canada between May 2010 and June 2013 (Figure S1B).

GXR administration and titration during the OL phase of the RWS were as described for the RCT. Response was defined as a $\geq 30 \%$ reduction in ADHD-RS-IV total score from baseline and a CGI-S rating of 1 (normal) or 2 (minimally ill) with tolerable side effects.

\section{Prior treatment}

For all participants who had previously received stimulant medication for ADHD, details of the last stimulant treatment (ie, stimulant treatment that occurred prior to the 3- to 35-day washout/screening period of study initiation) and reasons for stopping were recorded at the baseline visit of both studies using a prespecified, standardized questionnaire (Prior Stimulant Medication Questionnaire). Duration of prior stimulant treatment was not recorded. The responses to each question were not mutually exclusive. Reasons for stopping the last prior medication were summarized. For participants who cited lack of efficacy as the reason for stopping, the reported reasons were subsequently reviewed by two clinicians to ensure the appropriate categorization of the response.

\section{Analysis methodology}

The analysis of response to GXR and ATX was conducted according to participants' prior stimulant-treatment status, as recorded in the Prior Stimulant Medication Questionnaire. Those who had received prior stimulants were grouped by the last stimulant received ("prior MPH" included any MPH preparation; "prior non-MPH" included any other stimulant medication for ADHD). The efficacy analysis was performed on the change in ADHD-RS-IV total score from baseline. For the RCT, the change at visit 15/end point for each prior treatment subgroup was compared for GXR or ATX versus placebo. For the OL phase of the RWS, where participants only received GXR, the change at visit $13 / \mathrm{OL}$ end point was summarized for prior treatment subgroups.

A priori, two levels of response were defined: a $\geq 50 \%$ or a $\geq 30 \%$ reduction from baseline in the ADHD-RS-IV total score. For each responder definition, the proportion of responders in each prior treatment subgroup was summarized for both studies, and for the RCT only the difference in the proportion of responders between treatment groups (GXR or ATX versus placebo) compared for each responder definition, with 95\% confidence intervals (CIs). Time to response (days) was also summarized for each responder definition by prior treatment subgroup for both studies, and compared between treatment groups for the RCT only.

The CGI-I and CGI-S ratings were collected at visit 15/ end point for the RCT and visit 13/OL endpoint for the RWS. For CGI-I, participants were classified as either "improved" (scores 1 or 2) or "not improved" (score of 3 or more combined into one category). For CGI-S, participants were 
classified as either "normal/borderline ill" (scores 1 or 2 ) or "mildly ill or greater" (score of 3 or more combined into one category). The percentages of participants meeting response criteria were summarized by prior treatment subgroup for both studies, and compared between treatment groups (GXR or ATX versus placebo) for the RCT only.

\section{Ad hoc analyses (RCT)}

Two further levels of response, which combined ADHDRS-IV scores and CGI-I, ${ }^{22}$ were defined in the RCT to explore differences between GXR or ATX and placebo responses in the full RCT study population: $a \geq 50 \%$ or $\geq 30 \%$ change from baseline in ADHD-RS-IV total score combined with a CGI-I score of 1 or 2.

\section{Statistical analyses}

All participants who were randomized and received at least one dose of investigational drug were included in the fullanalysis set for each trial. Data from the RCT and RWS were analyzed separately. $P$-values were not adjusted for increased type I error, due to multiple end points and multiple comparisons, and are presented as descriptive statistics. No head-to-head comparison between GXR and ATX was made. Results with $P<0.05$ were regarded as nominally significant.

\section{RCT}

In the RCT, the efficacy analyses conducted on the change in ADHD-RS-IV score from baseline to visit 15/end point between GXR or ATX and placebo used an analysis of covariance model, which included terms for treatment group (effect of interest), the corresponding baseline score (covariate), and blocking factors of age-group (6-12 or 13-17 years) and country. Countries with low recruitment in the RCT were pooled into three groups (Italy, Austria, France, Sweden, Ireland, and the UK; Poland and Romania; the US and Canada); the other countries (Germany, Spain, Ukraine) were left unpooled. The least squares (LS) means and standard error of the mean for the treatment groups, difference in LS means between the treatment groups with $95 \%$ CIs, ES with 95\% CIs (calculated as the absolute difference in LS means between active treatment and placebo, divided by the root-mean-square error), and $P$-values for differences between treatment groups were calculated.

The proportion of responders was compared between active treatment groups and placebo using a CochranMantel-Haenszel test stratified by age-group and country. Summary statistics for time to response (in days) and KaplanMeier estimates of the 25 th percentile, median, and 75 th percentile (and corresponding 95\% CIs) were calculated for each treatment group. CGI-I and CGI-S data were analyzed using a Cochran-Mantel-Haenszel test stratified by agegroup and country to examine treatment-group effects at visit 15/end point in the RCT. The last observation carried forward approach was used to impute missing data for the efficacy analyses. Missing data were carried forward for all visits except baseline.

\section{RWS}

Data from the RWS were tabulated and are presented only descriptively.

\section{Results Participants}

The overall participant disposition is shown in Figure 1. Of 337 participants randomized and treated in the RCT, 163 $(48.4 \%)$ reported prior stimulant medication use via the Prior Stimulant Medication Questionnaire (placebo, $\mathrm{n}=56$; GXR, n=53; ATX, n=54) (Table 1). A total of 142 (42.1\%) participants reported that their last prior stimulant was a formulation of MPH (placebo, n=48; GXR, n=46; ATX, $\mathrm{n}=48$ ). One participant randomized to GXR who reported prior MPH use did not provide any post-baseline efficacy data, and was therefore excluded from the efficacy analysis. Owing to the small number of participants who reported receiving a non-MPH stimulant $(n=21,6.2 \%)$, and the heterogeneity of prior non-MPH treatments received, this subgroup was excluded from further reporting. Analysis of the ADHD-RS-IV efficacy end point on the full data set including these participants showed that their exclusion had no overall effect on the results (see "Supplementary materials" and Table S1). The remaining 174 (51.6\%) participants were classified as stimulant-naïve (placebo, $n=55$; GXR, $n=61$; ATX, $n=58$ ). The total number of participants reporting prior ATX use $(n=40,11.9 \%)$ was considered too small for further investigation.

Of 503 participants treated in the OL phase of the RWS, 296 (58.8\%) participants reported prior stimulantmedication use (Table 1$)$. Only $72(14.3 \%)$ reported that their last prior stimulant was a non-MPH treatment; again, data from this subgroup were not reported, leaving 224 (44.5\%) participants who reported that their last prior stimulant was an MPH medication and 207 (41.2\%) who were stimulant-naïve.

Baseline demographics and disease characteristics for the RCT ( $n=337)$ and the RWS ( $=526$, with $n=503$ included in the full-analysis set) are shown in Table 2. Details of the full trial populations are published in greater detail elsewhere. ${ }^{19-21}$ 

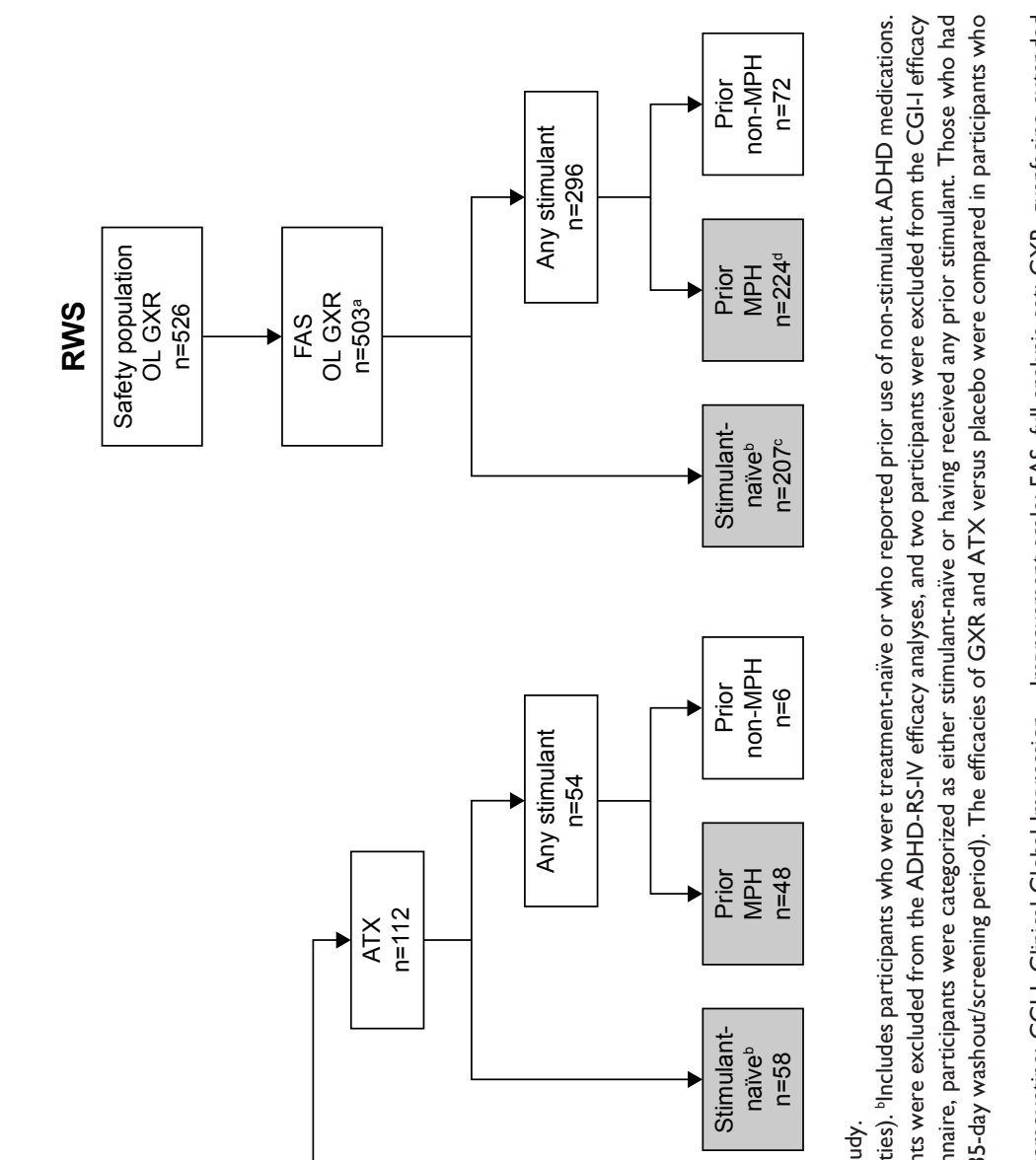

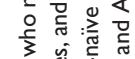

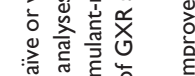

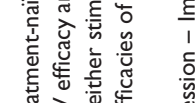

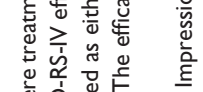

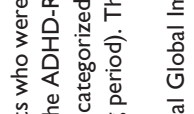

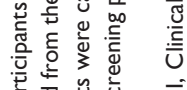

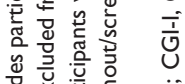

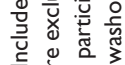

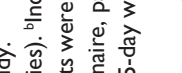

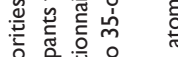

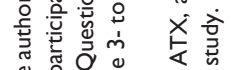
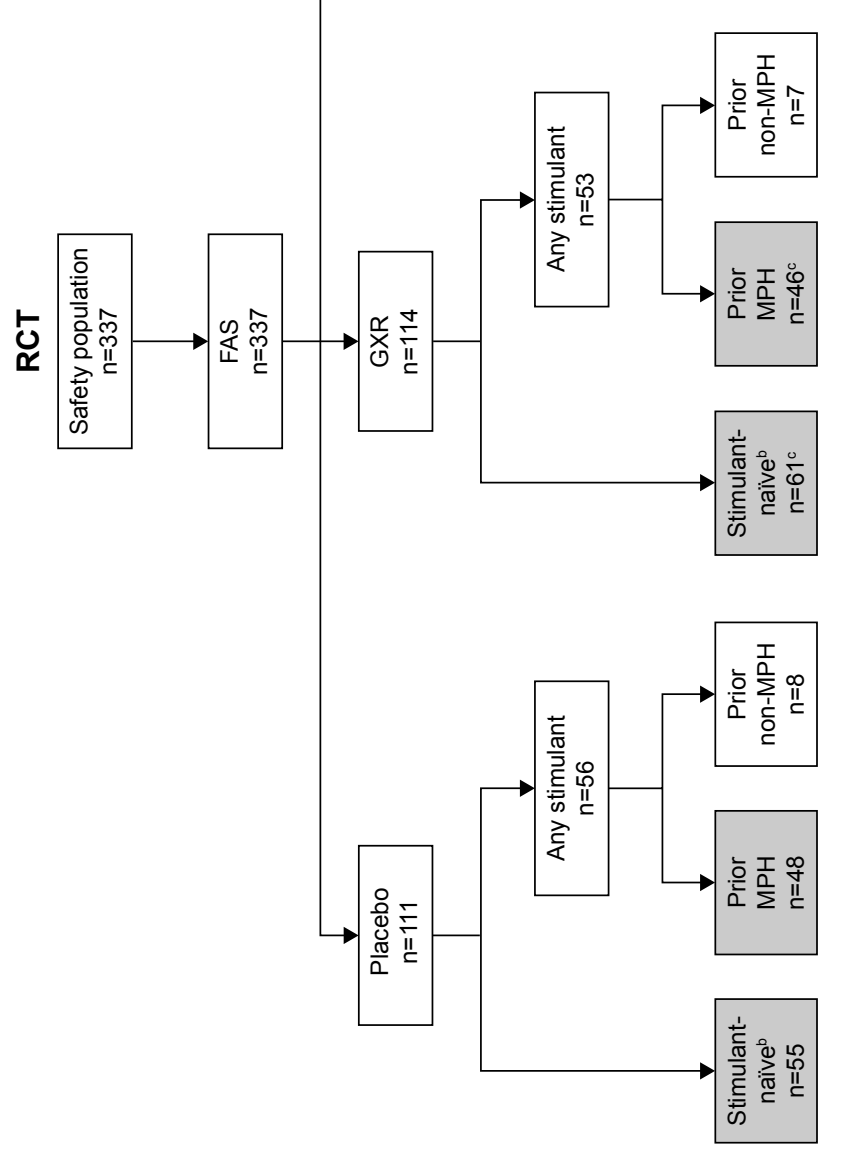

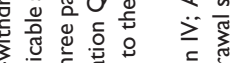

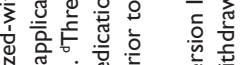

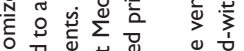

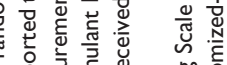

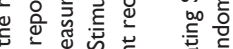

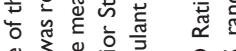

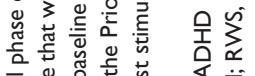

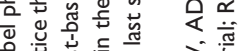

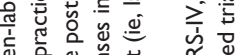

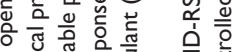

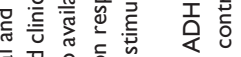

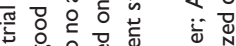

प0口

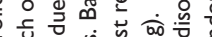

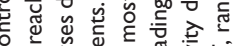

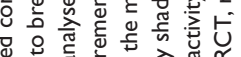

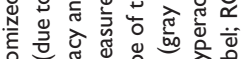

$\overline{0}$ 过

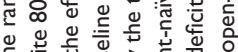

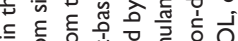

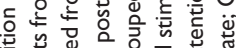

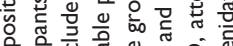

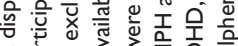

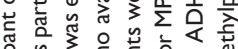

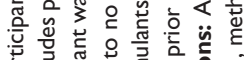

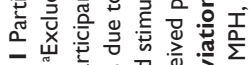

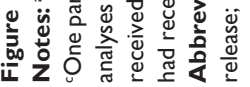


Table I Summary of prior stimulant medications

\begin{tabular}{|c|c|c|c|c|c|}
\hline \multirow[t]{2}{*}{ Prior ADHD medication used } & \multicolumn{4}{|l|}{ RCT } & \multirow{2}{*}{$\frac{\text { RWS }}{\text { GXR (n=503) }}$} \\
\hline & Placebo $(n=I \mid I)$ & $\operatorname{GXR}(n=|| 4)$ & $\operatorname{ATX}(n=\mid 12)$ & Total $(n=337)$ & \\
\hline Prior MPH use, $n(\%)$ & $48(43.2)$ & $46(40.4)$ & $48(42.9)$ & $142(42.1)$ & $224(44.5)$ \\
\hline $\mathrm{MPH}, \mathrm{n}(\%)$ & $45(40.5)$ & $46(40.4)$ & $47(42.0)$ & $138(40.9)$ & $205(40.8)$ \\
\hline Dexmethylphenidate, n (\%) & $3(2.7)$ & 0 & I $(0.9)$ & $4(1.2)$ & $19(3.8)$ \\
\hline Prior non-MPH use, $n$ (\%) & $8(7.2)$ & $7(6.1)$ & $6(5.4)$ & $21(6.2)$ & $72(14.3)$ \\
\hline Mixed amphetamine salts, $\mathrm{n}(\%)$ & $3(2.7)$ & $2(1.7)$ & $3(2.6)$ & $8(2.4)$ & $30(6.0)$ \\
\hline Amphetamine, $n(\%)$ & $\mathrm{I}(0.9)$ & 0 & $2(1.8)$ & $3(0.9)$ & $\mathrm{I}(0.2)$ \\
\hline Dextroamphetamine, $\mathrm{n}(\%)$ & $\mathrm{I}(0.9)$ & 0 & 0 & $\mathrm{I}(0.3)$ & $2(0.4)$ \\
\hline Lisdexamfetamine, $n(\%)$ & $3(2.7)$ & $5(4.4)$ & $\mathrm{I}(0.9)$ & $9(2.7)$ & $39(7.7)$ \\
\hline
\end{tabular}

Note: Prior stimulant medication as named by participants in the Prior Stimulant Medication Questionnaire.

Abbreviations: ADHD, attention-deficit/hyperactivity disorder; ATX, atomoxetine; GXR, guanfacine extended release; MPH, methylphenidate; RCT, randomized controlled trial; RWS, randomized-withdrawal study.

Mean (standard deviation [SD]) ages between groups/studies ranged from $10.1(2.8)$ years to $11.5(2.5)$ years, the majority of participants in both studies were boys, and there tended to be more boys in each of the prior MPH subgroups. The combined subtype of ADHD was most prevalent in all subgroups.

Mean (SD) weight-adjusted dose of GXR at the end of the RCT was $0.09(0.03) \mathrm{mg} / \mathrm{kg} /$ day for both prior MPH and stimulant-naïve subgroups. For ATX, the final weightadjusted doses were $1.0(0.27) \mathrm{mg} / \mathrm{kg} /$ day and $1.0(0.22)$ $\mathrm{mg} / \mathrm{kg} /$ day for prior MPH and stimulant-naïve subgroups, respectively. At the end of the OL phase in the RWS, the mean (SD) weight-adjusted dose of GXR was 0.09 $(0.03) \mathrm{mg} / \mathrm{kg} /$ day for the prior MPH subgroup and $0.08(0.03)$ $\mathrm{mg} / \mathrm{kg} /$ day for the stimulant-naïve subgroup.

\section{Reasons for stopping MPH treatment}

Reasons provided on the Prior Stimulant Medication Questionnaire for stopping MPH treatment are shown in Table 3. In the RCT, reasons included lack of effectiveness (56\%), side effects (37\%), and wanting to switch medication (29\%); in the RWS, reasons included lack of effectiveness $(65 \%)$, side effects $(55 \%)$, and wanting to stop taking stimulant medication $(11 \%)$.

Table 2 Participant baseline characteristics and demographic data from the RCT (safety population/full-analysis set) and the RWS (safety population), according to prior stimulant-medication status

\begin{tabular}{|c|c|c|c|c|c|c|c|c|}
\hline \multirow[t]{4}{*}{ Characteristic } & \multicolumn{6}{|l|}{ RCT } & \multirow{2}{*}{\multicolumn{2}{|c|}{$\frac{\text { RWS }}{n=526^{a}}$}} \\
\hline & \multicolumn{2}{|c|}{ Placebo $(n=I I I)$} & \multicolumn{2}{|c|}{ GXR (n=I | 4) } & \multicolumn{2}{|c|}{$\operatorname{ATX}(n=I \mid 2)$} & & \\
\hline & $\begin{array}{l}\text { Prior } \\
\text { MPH }\end{array}$ & $\begin{array}{l}\text { Stimulant- } \\
\text { naïve }\end{array}$ & $\begin{array}{l}\text { Prior } \\
\text { MPH }\end{array}$ & $\begin{array}{l}\text { Stimulant- } \\
\text { naïve }\end{array}$ & $\begin{array}{l}\text { Prior } \\
\text { MPH }\end{array}$ & $\begin{array}{l}\text { Stimulant- } \\
\text { naïve }\end{array}$ & $\begin{array}{l}\text { Prior } \\
\text { MPH }\end{array}$ & $\begin{array}{l}\text { Stimulant- } \\
\text { naïve }\end{array}$ \\
\hline & $n=48$ & $\mathrm{n}=\mathbf{5 5}$ & $n=46$ & $n=61$ & $n=48$ & $\mathrm{n}=\mathbf{5 8}$ & $n=227$ & $\mathbf{n}=\mathbf{2 2 7}$ \\
\hline Age (years), mean (SD) & $11.0(2.32)$ & $10.7(3.04)$ & II.5 (2.52) & $10.4(2.97)$ & $10.8(2.79)$ & $10.3(2.86)$ & $10.9(2.52)$ & I0.I (2.76) \\
\hline Male, n (\%) & $4 \mathrm{I}(85.4)$ & $42(76.4)$ & $33(71.7)$ & 39 (63.9) & $42(87.5)$ & $4 \mathrm{l}(70.7)$ & $173(76.2)$ & $163(7 \mid .8)$ \\
\hline BMI $\left(\mathrm{kg} / \mathrm{m}^{2}\right)$, mean $(\mathrm{SD})$ & $18.29(2.48)$ & $19.08(2.85)$ & $18.52(3.11)$ & $|8.8|(2.93)$ & $|8.7|(3.12)$ & $18.77(2.86)$ & $18.38(2.84)$ & $18.98(2.85)$ \\
\hline \multicolumn{9}{|l|}{ ADHD subtype, $n(\%)$} \\
\hline Predominantly inattentive & $3(6.3)$ & $7(12.7)$ & $10(21.7)$ & $3(4.9)$ & $4(8.3)$ & $6(10.3)$ & $28(12.3)$ & $31(13.7)$ \\
\hline Predominantly hyperactive-impulsive & $\mathrm{I}(2.1)$ & $4(7.3)$ & I (2.2) & $5(8.2)$ & 0 & $3(5.2)$ & II (4.8) & $7(3.1)$ \\
\hline Combined & $44(91.7)$ & $44(80.0)$ & $35(76.1)$ & $53(86.9)$ & $44(91.7)$ & $49(84.5)$ & I88 (82.8) & $189(83.3)$ \\
\hline Baseline ADHD-RS-IV score, mean (SD) & $43.7(5.34)$ & $42.7(5.7 \mathrm{I})$ & $43.5(5.44)$ & $42.7(5.57)$ & $44.7(5.55)$ & $42.7(5.98)$ & $45.1(6.02)$ & 42.7 (6.39) \\
\hline \multicolumn{9}{|c|}{ Baseline CGI-S, n (\%) } \\
\hline Moderately ill & II (22.9) & $18(32.7)$ & $3(6.5)$ & $17(27.9)$ & $3(6.3)$ & $17(29.3)$ & $35(15.4)$ & $60(26.4)$ \\
\hline Markedly ill & $18(37.5)$ & $28(50.9)$ & $21(45.7)$ & $34(55.7)$ & $25(52.1)$ & $28(48.3)$ & $103(45.4)$ & $123(54.2)$ \\
\hline Severely ill & $18(37.5)$ & $8(14.5)$ & $19(41.3)$ & $10(16.4)$ & $18(37.5)$ & $13(22.4)$ & $66(29.1)$ & $4 \mid(18.1)$ \\
\hline Among the most extremely ill & $\mathrm{I}(2 . \mathrm{I})$ & $\mathrm{I}(\mathrm{I} .8)$ & $3(6.5)$ & 0 & $2(4.2)$ & 0 & $23(10.1)$ & $3(1.3)$ \\
\hline $\begin{array}{l}\text { Baseline CPRS-R:L oppositional subscale } \\
\text { score, mean (SD) }\end{array}$ & $15.0(7.22)$ & $13.3(6.85)$ & $14.8(7.92)$ & $13.0(6.47)$ & $16.3(7.00)$ & $14.4(7.20)$ & I $6.5(7.96)$ & I5.5 (7.42) \\
\hline
\end{tabular}


Table 3 Summary of reasons for stopping prior MPH treatment, by treatment (full-analysis set)

\begin{tabular}{|c|c|c|c|c|c|}
\hline \multirow[t]{2}{*}{ Reason for stopping prior MPH, n (\%) ${ }^{a}$} & \multicolumn{4}{|l|}{ RCT } & \multirow{2}{*}{$\begin{array}{l}\text { RWS } \\
\text { GXR } \\
(n=503)\end{array}$} \\
\hline & $\begin{array}{l}\text { Placebo } \\
(n=I I I)\end{array}$ & $\begin{array}{l}\text { GXR } \\
(n=|| 4)\end{array}$ & $\begin{array}{l}\text { ATX } \\
(n=|| 2)\end{array}$ & $\begin{array}{l}\text { Total } \\
(n=337)\end{array}$ & \\
\hline Number of participants $(n)$ & 48 & 46 & 48 & 142 & 224 \\
\hline Not effective & $28(58.3)$ & $25(54.3)$ & $27(56.3)$ & $80(56.3)$ & $145(64.7)$ \\
\hline Did not work & $7(14.6)$ & $6(13.0)$ & $9(18.8)$ & $22(15.5)$ & $28(12.5)$ \\
\hline Effect did not last long enough & $7(14.6)$ & $7(15.2)$ & $9(18.8)$ & $23(16.2)$ & $40(17.9)$ \\
\hline Was not optimal per the participant/parent/caregiver & $19(39.6)$ & $18(39.1)$ & $18(37.5)$ & $55(38.7)$ & $91(40.6)$ \\
\hline Was not optimal per the participant's physician & $8(16.7)$ & $7(15.2)$ & $14(29.2)$ & $29(20.4)$ & $31(13.8)$ \\
\hline Other & $\mathrm{I}(2 . \mathrm{I})$ & $2(4.3)$ & 0 & $3(2.1)$ & $13(5.8)$ \\
\hline Because the ADHD medication had side effects & $18(37.5)$ & $18(39.1)$ & $17(35.4)$ & $53(37.3)$ & $122(54.5)$ \\
\hline Wanted to switch to another medication & $15(31.3)$ & $15(32.6)$ & II (22.9) & $41(28.9)$ & $12(5.4)$ \\
\hline Wanted to stop taking MPH & $7(14.6)$ & $8(17.4)$ & $9(18.8)$ & $24(16.9)$ & $25(11.2)$ \\
\hline Could not afford to pay for medication & $\mathrm{I}(2.1)$ & $4(8.7)$ & $\mathrm{I}(2.1)$ & $6(4.2)$ & $10(4.5)$ \\
\hline Wanted to stop taking any ADHD medication & 0 & $2(4.3)$ & $2(4.2)$ & $4(2.8)$ & I $(0.4)$ \\
\hline Wanted to switch to nonpharmacological interventions to treat ADHD & 0 & 0 & 0 & 0 & 0 \\
\hline Other & I (2.I) & 0 & 0 & $\mathrm{I}(0.7)$ & $13(5.8)$ \\
\hline
\end{tabular}

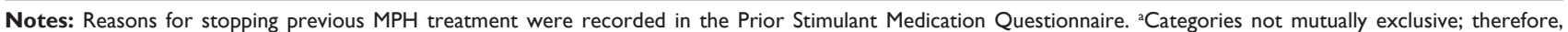
columns may total $>100 \%$. Includes participants who took prior MPH, as confirmed by medical review of medication names provided in the questionnaire. Percentages based on the number of participants who took prior MPH in the respective subgroups.

Abbreviations: ADHD, attention-deficit/hyperactivity disorder; ATX, atomoxetine; GXR, guanfacine extended release; MPH, methylphenidate; RCT, randomized controlled trial; RWS, randomized-withdrawal study.

\section{Efficacy analyses by prior treatment subgroup \\ Change from baseline in ADHD-RS-IV}

Mean changes from baseline to end point in ADHD-RS-IV score for each study are shown in Figure 2. In the RCT, nominally significant placebo-adjusted differences in LS mean change from baseline to end point on the ADHD-RS-IV were observed in GXR-treated participants, in both subgroups (prior MPH, $-9.8[95 \% \mathrm{CI}-14.6$ to -5.1$], P<0.001, \mathrm{ES} 0.85$ stimulant-naïve: -7.6 [95\% CI -11.8 to -3.3 ],$P<0.001$, ES 0.65). In ATX-treated participants, a nominally significant placebo-adjusted difference in LS mean change from baseline to end point in ADHD-RS-IV was seen in the stimulant-naïve subgroup but not the prior MPH subgroup (prior MPH, -1.8

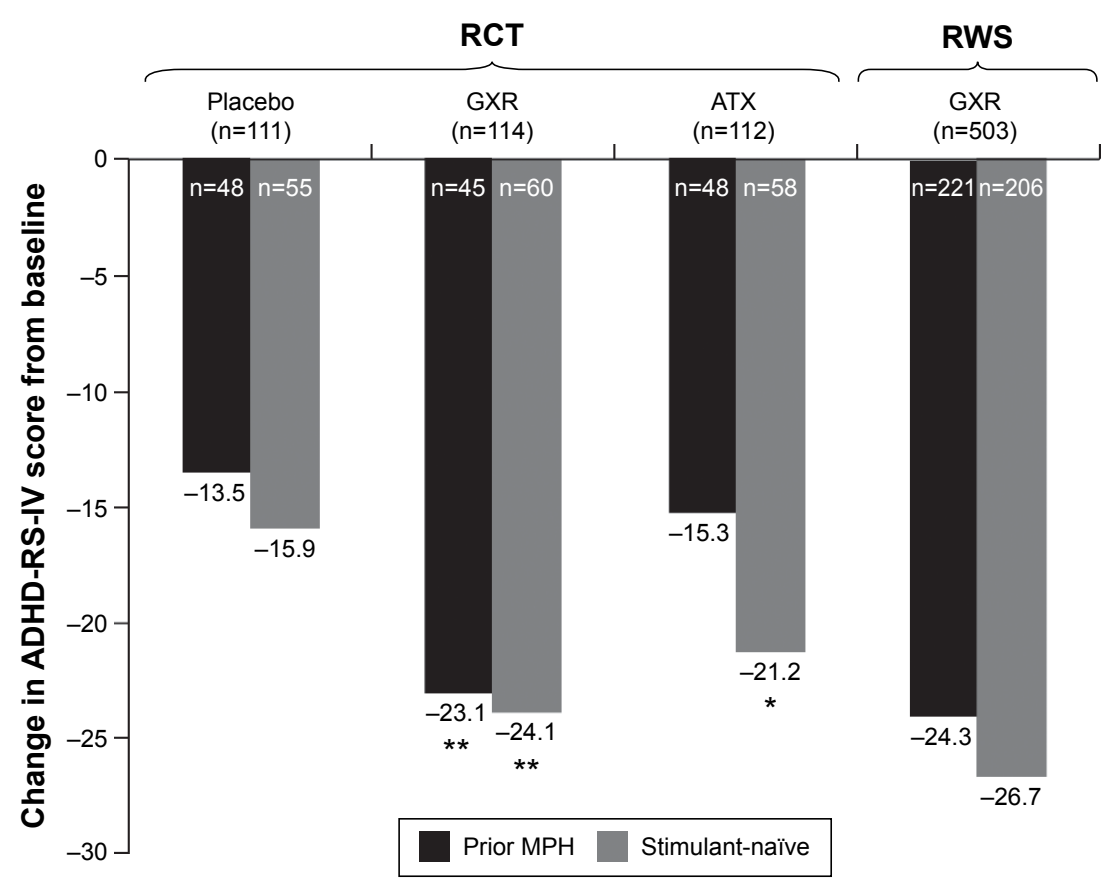

Figure 2 Mean change from baseline in ADHD-RS-IV total score by treatment for prior MPH or stimulant-naïve subgroups at endpoint (full-analysis set).

Notes: $* P<0.05 ; * * P<0.001$ versus placebo. Nominal statistical differences based on ANCOVA of placebo-adjusted LS means in the RCT only. Statistics not performed for RWS. Not all patients had ADHD-RS-IV total score data available at end point.

Abbreviations: ADHD-RS-IV, ADHD Rating Scale version IV; ANCOVA, analysis of covariance; ATX, atomoxetine; GXR, guanfacine extended release; LOCF, last observation carried forward; LS, least squares; MPH, methylphenidate; RCT, randomized controlled trial; RWS, randomized-withdrawal study. 
[95\% CI -6.5-2.9], $P>0.05$, ES 0.15; stimulant-naïve, -5.0 [95\% CI -9.4 to -0.7 ], $P=0.022$, ES 0.43 ).

In the OL phase of the RWS, changes from baseline in ADHD-RS-IV total score for GXR-treated participants were similar in the prior MPH and stimulant-naïve subgroups (Figure 2).

As prior MPH treatment may influence the placebo effect indirectly due to patients' prior experience and expectations of the effects of MPH treatment, or by any other neurobiological or psychological pathway, we also compared placebo response in the subgroups. Placebo response in the RCT (ADHD-RS-IV total score change from baseline $[95 \% \mathrm{CI}]$ ) was lower for prior MPH patients (-13.5 [-17.4 to -9.5$])$ than stimulant-naïve patients (-15.9 [-19.0 to -12.8$])$, although the overlapping CIs indicate that the difference was not significant.

The efficacy analysis by reason for stopping prior treatment is reported in the "Supplementary materials" section (Table S2).

\section{Responder analysis}

Responder analyses from the RCT are shown in Table 4. The difference from placebo in the proportion of participants achieving a $\geq 50 \%$ reduction from baseline in ADHDRS-IV total score was nominally significant in GXR-treated participants in both the prior MPH-treated and stimulantnaïve subgroups (difference from placebo [95\% CI]: prior MPH, 24.2\% [4.7-43.6], $P=0.011$; stimulant-naïve, 25.5\% [7.8-43.1], $P=0.003)$. In ATX-treated participants, nominally significant differences versus placebo were seen only in the stimulant-naïve subgroup (difference from placebo [95\% CI]: prior MPH, 2.1\% [ -16.3 to 20.4$], P=0.911$; stimulant-naïve, $22.4 \%$ [4.5-40.3], $P=0.010$ ).

A similar pattern of results was noted in the proportion of participants achieving a $\geq 30 \%$ reduction from baseline in ADHD-RS-IV total score. A nominally significantly higher proportion of GXR-treated participants achieved this response regardless of prior treatment status (difference from placebo [95\% CI]: prior MPH, 27.8\% [9.1-46.4], $P=0.008$; stimulant-naïve, 25.2\% [9.1-41.2], $P<0.001)$. For ATXtreated participants, again, only the stimulant-naïve subgroup achieved a $\geq 30 \%$ response (19.4\% [2.5-36.3], $P=0.008$; prior MPH, $8.3 \%$ [ -11.5 to 28.2$], P=0.511)$.

In the OL phase of the RWS, there were $9.1 \%$ more participants achieving a $\geq 50 \%$ reduction from baseline in ADHD-RS-IV total score with GXR in the stimulant-naïve subgroup compared with the prior MPH subgroup (73.8\% [67.8\%-79.8\%], 64.7\% [58.4\%-71.0\%]); a $\geq 30 \%$ reduction from baseline ADHD-RS-IV total score was achieved by

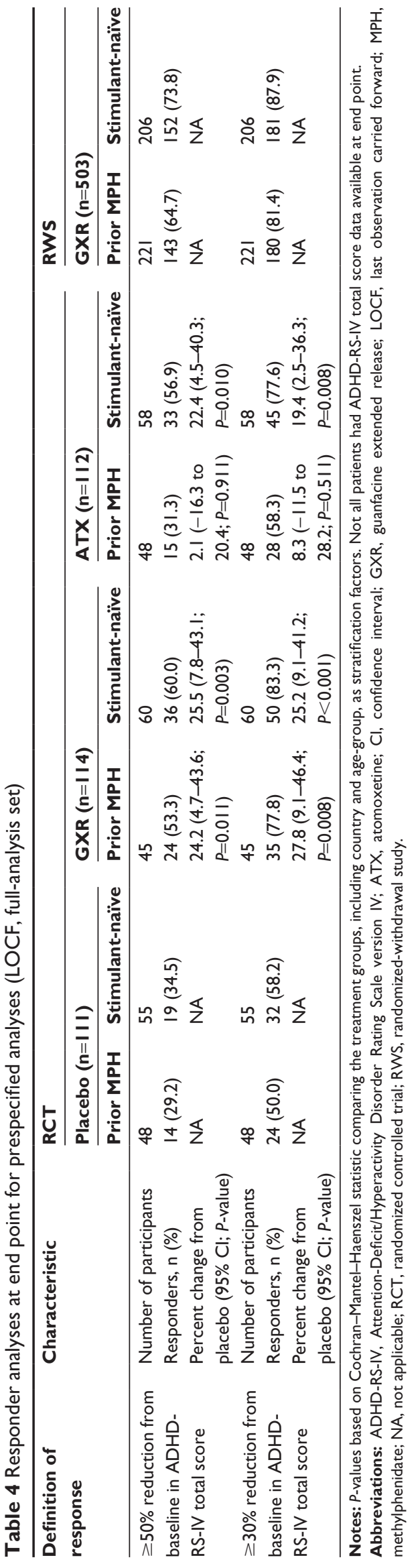




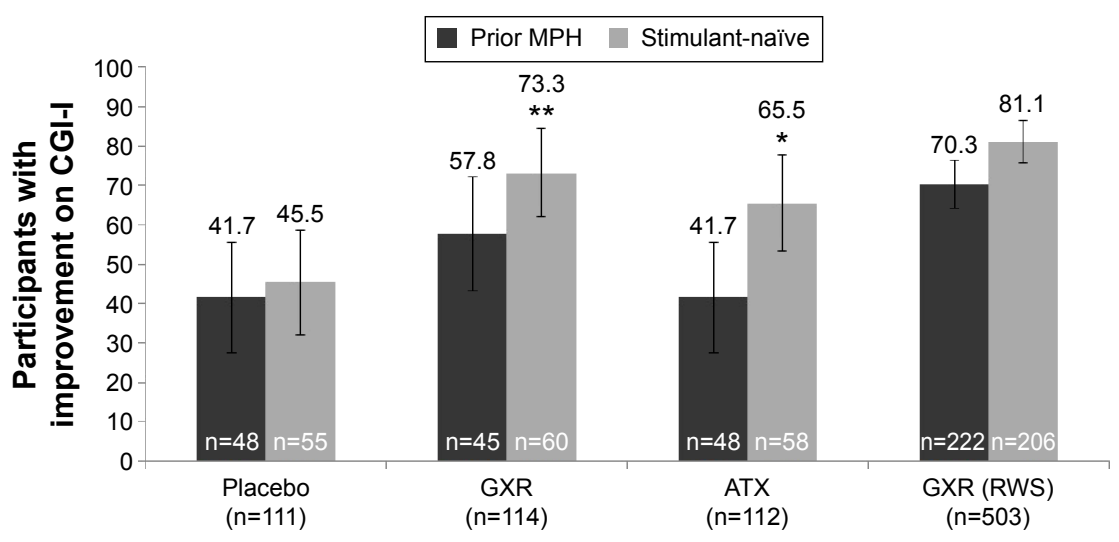

Figure 3 Proportion of participants with improved (\%) CGI-I (scores of I or 2), at end point, by treatment in prior MPH or stimulant-naive subgroups (LOCF; full-analysis set). Notes: $* P=0.005 ; * * P<0.001$ versus placebo; error bars represent $95 \%$ confidence intervals. Improved includes CGI-I categories "very much improved" and "much improved".

Abbreviations: ATX, atomoxetine; CGI-I, Clinical Global Impression - Improvement scale; GXR, guanfacine extended release; LOCF, last observation carried forward; $\mathrm{MPH}$, methylphenidate; RCT, randomized controlled trial; RWS, randomized-withdrawal study.

$6.5 \%$ more participants in the stimulant-naïve subgroup than the prior MPH subgroup (87.9\% [83.4\%-92.3\%], 81.4\% [76.3\%-86.6\%]).

The time-to-response analysis is reported in the "Supplementary materials" section (Table S3).

\section{CGI-I and CGI-S}

In the RCT, among stimulant-naïve participants, a nominally significantly higher proportion of GXR- and ATX-treated participants had improved CGI-I (score of 1 or 2) at end point compared with placebo (Figure 3; difference $[95 \%$ CI]: GXR, 27.9\% [10.6\%-45.2\%], $P<0.001$; ATX, 20.1\% $[2.1 \%-38.0 \%], P=0.005)$. However, no nominally significant difference versus placebo was seen in the prior $\mathrm{MPH}$ subgroup (GXR, 16.1\% [-4.0\% to 36.2\%], $P=0.090$; ATX, $0[-19.7 \%$ to $19.7 \%], P=0.857)$. In the OL RWS, $10.8 \%$ more participants treated with GXR had improved CGI-I scores at end point in the stimulant-naïve subgroup compared with the prior MPH subgroup.

Also in the RCT, at end point, there were no significant differences in proportion of participants categorized as normal/borderline ill (CGI-S score of 1 or 2) from placebo among those treated with GXR or ATX in the prior MPH (difference [95\% CI]: GXR, 16.8\% [-1.0\% to $34.6 \%$ ], $P=0.070$; ATX, $-4.2 \%$ [-19.1\% to $10.7 \%], P=0.516)$ and stimulant-naïve subgroups (difference [95\% CI]: GXR, $12.7 \%$ [ $-4.4 \%$ to $29.8 \%$ ], $P=0.073$; ATX, $7.2 \%$ [ $-9.8 \%$ to $24.2 \%], P=0.242$ ) (Table S4).

\section{Ad hoc analyses (RCT only)}

Responder analyses showed nominally significant differences versus placebo in GXR- and ATX-treated participants at both combined response levels (Table S5). For the $\geq 30 \%$ combined response level, differences $(95 \% \mathrm{CI})$ in the percentage of responders from placebo were $21.9 \%$ (9.2\%-34.7\%, $P<0.001)$ for GXR-treated participants and 13.0\% (0-26.0\%, $P=0.017$ ) for ATX-treated participants. For the $\geq 50 \% \mathrm{com}$ bined response level, differences from placebo $(95 \% \mathrm{CI})$ were $23.8 \%(11.3 \%-36.4 \%, P<0.001)$ for GXR-treated participants and $12.2 \%(-0.2 \%$ to $24.7 \%, P=0.018)$ for ATX-treated participants.

\section{Safety}

For the full study population in the RCT, $77.2 \%$ of those receiving GXR, $67.9 \%$ of those receiving ATX, and $65.8 \%$ of those in the placebo group reported treatment-emergent adverse events (TEAEs). ${ }^{19}$ Serious TEAEs considered related to treatment were reported in one participant in the placebo group and one in the GXR group, with the latter leading to discontinuation. Overall in the RCT, a low proportion of participants discontinued due to TEAEs (0.9\% placebo, $7.9 \%$ GXR, $4.5 \%$ ATX).${ }^{19}$ In the OL phase of the RWS, $85.2 \%$ of participants reported TEAEs. ${ }^{20,21}$ There were five serious adverse events (AEs) considered related to treatment, three of which led to discontinuation. Overall, in the OL phase of the RWS, $8.0 \%$ of participants discontinued due to TEAEs.

\section{Discussion}

This study examined whether prior treatment with MPH affects response to GXR using prespecified analyses of data from two international Phase III studies. GXRtreated participants demonstrated nominally statistically significant improvements in all ADHD-symptom measures 
(ADHD-RS-IV scores, responder analyses, and time to response) in both stimulant-naïve and prior MPH-treated participants compared with placebo. ADHD-symptom improvements in ATX-treated participants separated from placebo, but not when ATX was given after prior MPH treatment. The clinical relevance of the analysis of GXR efficacy in individuals with ADHD who had previously received MPH is highlighted by the approval of GXR in Europe for children and adolescents for whom stimulants are not suitable, not tolerated, or have been shown to be ineffective. ${ }^{14}$

The finding of a relatively lower response to ATX in participants previously treated with MPH compared with stimulant-naïve participants is consistent with previous findings from a randomized, double-blind, placebo-controlled study comparing ATX, MPH, and placebo over a 6-week period. ${ }^{17}$ In the acute comparison phase, for participants previously treated with a stimulant, the mean (SD) change from baseline in ADHD-RS-IV scores was significantly different between the MPH-treated group (-15.1 [13.1]) and the ATX-treated group ( -12.4 [12.2], $P=0.04)$, and the proportion of responders ( $40 \%$ decrease in ADHD-RS-IV score from baseline to end point) in the ATX group (37\%) was not significantly different from placebo (23\%). A metaregression analysis of 25 double-blind RCTs of ATX also showed a significant relationship between treatment naïveté and degree of response to ATX, with the greater response in those naïve to ADHD treatment ${ }^{18}$ supporting the suggestion of a difference in response to ATX depending on prior treatment.

Shared mechanisms between stimulants and ATX may explain how a previous inadequate response to MPH may predict a poorer outcome to subsequent treatment with ATX than it does for GXR. Both MPH and ATX block uptake of extracellular catecholamines. Although ATX is selective for the noradrenaline transporter, because dopamine reuptake in the prefrontal cortex is primarily managed by the noradrenaline transporter, ATX, such as MPH, increases extracellular concentrations of both noradrenaline and dopamine in this region. ${ }^{15,23,24}$ Further, prior treatment with stimulants may change susceptibility to subsequent drug treatment at either a pharmacological or physiological psychological level; striatal dopamine-transporter density has been found to be increased in individuals previously treated with stimulants, possibly due to adaptation of the brain to continuous dopamine-transporter blockade. ${ }^{25,26}$ In contrast, GXR is a direct and selective agonist for $\alpha 2 \mathrm{~A}$-adrenergic receptors and does not directly affect transporter function, hence there is limited overlap with the mechanism of action of stimulants.
Reports that genetic variants in the CES1 gene encoding the major MPH-metabolizing enzyme and the dopaminetransporter gene $S L C 6 A 3$ affect the response or side-effect profile of $\mathrm{MPH}^{27,28}$ suggest that genetic biomarkers of response to ADHD medications are an important avenue for future research. However, this discussion notwithstanding, it should be noted that not all participants previously treated with MPH in this analysis necessarily had an inadequate response, as other reasons for stopping prior MPH treatment were also given (although inadequate response was a primary reason for stopping MPH).

The RWS was analyzed to provide GXR data from a larger data set regarding response to GXR in participants who were previously treated with MPH or stimulant-naïve, and generally confirmed the findings in direction and magnitude of response seen in the RCT. Similarly, the ad hoc analyses of combined ADHD-RS-IV and CGI-I responses at two thresholds confirmed that both GXR and ATX treatments gave robust responses in the RCT compared with placebo.

Responder analyses are widely accepted in the field, although there is currently no consensus regarding the most appropriate response criteria; previous analyses of ADHD treatments have employed specified percentage reductions from baseline in ADHD-RS-IV total score, a CGI-I score of 1 or 2, or a combination of the two. ${ }^{3,29-31}$ The use of different levels of response in the present study provides information at different levels of stringency. Response rates decreased with increasingly stringent definitions, as would be expected. We also found that generally the same trend or outcome was found, regardless of the definition used.

Both GXR and ATX significantly improved CGI-I scores at RCT end point compared with placebo in the stimulantnaïve subgroup; however, no statistical improvement relative to placebo was seen in the prior MPH subgroup for either GXR- or ATX-treated participants. For GXR, this result approached but did not reach nominal significance $(P=0.09)$, which is in contrast to the ADHD-RS-IV results. There was no nominally significant difference between GXR or ATX and placebo in either the stimulant-naïve or prior MPH subgroups in the proportion of participants at end point with CGI-S scores indicating "normal/borderline" severity of symptoms, although for GXR this result approached nominal significance in the stimulant-naïve $(P=0.073)$ and prior $\mathrm{MPH}$ $(P=0.07)$ subgroups. The OL phase of the RWS showed a much greater degree of improvement in CGI-S to that seen in the RCT, possibly as a result of the OL nature of the study. It is not entirely clear why the CGI measure was less sensitive than the ADHD-RS-IV to detect medication effects in 
this study, although the ordinal (CGI-I) versus continuous (ADHD-RS) characteristics of these assessments may have been a factor. Given this result, and the indirect nature of the comparison between GXR and ATX in the current study design, more systematic research is required.

\section{Limitations}

Our findings should be interpreted in the context of several limitations. With regard to study design, the current analyses were not originally powered for a head-to-head comparison between the active treatments (the study was designed to detect differences between active treatment arms and placebo based on the ADHD-RS-IV); however, these analyses were prespecified in the original study protocols in a separate statistical analysis plan prior to database lock. The categorization of participants as prior MPH or stimulant-naïve was based on responses to the Prior Stimulant Medication Questionnaire. Once analyses were complete, a small subset of non-MPH-treated participants in the prior stimulant group were excluded, which slightly reduced the sample size. However, a sensitivity analysis of the full prior stimulant group showed that this exclusion did not affect the overall results. Children and adolescents previously treated with nonstimulants were likewise excluded from this study, because the number of such participants in the present studies were too small to permit such analyses. There are also a number of considerations related to the recording of previous treatment. In the Prior Stimulant Medication Questionnaire, the reasons for stopping prior medication were not mutually exclusive, as participants could give more than one reason. Participants who claimed efficacy failure had no clinical measures recorded to indicate the degree of inadequate response to prior treatment, nor the number of trials or duration of prior therapies. We also had no information on whether the dosing or titration of prior MPH treatment was adequate, and thus no stratification for potential prior dosage differences was possible at randomization.

It is also acknowledged that although both GXR and ATX were dose-optimized in the RCT based on the respective prescribing information/summary of product characteristics for each product, the clinically recommended dose for ATX $(1.2 \mathrm{mg} / \mathrm{kg})$ is somewhat higher than the mean end-oftreatment dose of $1.0 \mathrm{mg} / \mathrm{kg}$ in the present study, possibly as the result of AEs or other factors that may have limited the ability to titrate ATX to the optimal dose rapidly. However, the 6-week maintenance-treatment period in the RCT did give sufficient time for participants to achieve their fullest potential response at the optimized dose for both medications. ${ }^{19}$
Finally, it should be noted that this study found a numerically but nominally statistically nonsignificant larger placebo response in the stimulant-naïve group than in the prior MPH group, supporting other research suggesting that previous MPH exposure may influence the placebo response. ${ }^{17,29}$ Future research, therefore, should specifically address the question of whether prior exposure to MPH changes the outcome on subsequent pharmacological exposure.

\section{Conclusion}

Although there are no published studies that address the sequential efficacy of ADHD medication as their primary objective, such studies as the present one can be informative. Subgroup analyses in this study highlight the importance of considering the medication history of children and adolescents with ADHD to help guide clinical intervention for individual patients, and ultimately algorithm development. As has been previously reported, secondary analyses of the RCT indirectly favored GXR versus ATX in a prespecified comparison of the change from baseline in ADHD-RS-IV total score at end point. ${ }^{19}$ Results from the prespecified analyses reported here suggest that the efficacy observed in participants treated with GXR but not ATX may be somewhat explained by the prior MPH-treated cohort. These are the first studies to examine differences in response to different nonstimulant medications as a function of prior stimulant exposure. However, even though prespecified, the present results are exploratory, and further research is needed to confirm these findings.

\section{Acknowledgments}

Research was funded by Shire Development LLC. Under the direction of the authors, Joanna Wright, DPhil, CMPP and Jackie Marchington, PhD, CMPP, employees of Caudex, Oxford, UK, and Eric Southam, PhD, CMPP, and Isabelle Kaufmann, PhD, employees of Oxford PharmaGenesis, Oxford, UK, provided writing assistance for this publication. Editorial assistance in formatting, proofreading, copyediting, and fact-checking was also provided by Caudex, Oxford, UK. Antonia Panayi of Shire International GmbH, Switzerland, also reviewed and edited the manuscript for scientific accuracy. Vanja Sikirica and Brigitte Robertson, employees of Shire Development LLC at the time of the study, and Andrew Lyne and Ralph Bloomfield, employees of Shire Development Ltd. at the time of the study, provided the statistical analyses and review for the publication. Shire International $\mathrm{GmbH}$, Switzerland provided funding to $\mathrm{Cau}-$ dex, Oxford, UK, and Oxford Pharmagenesis, Oxford, UK 
for support in writing and editing this manuscript. Shire manufactures and distributes drugs for the treatment of ADHD. Although employees of the sponsor were involved in the design, collection, analysis, interpretation, and factchecking of information, the content of this manuscript, the interpretation of the data, and the decision to submit the manuscript for publication in Neuropsychiatric Disease and Treatment was made by the authors independently.

\section{Disclosure}

$\mathrm{MH}$ is a member of advisory boards and has spoken at educational events for Eli Lilly, Janssen Cilag, Medice, Novartis, and Shire, and has received consultation fees from Engelhard Arzneimittel, Medice, Shire, and Steiner Arzneimittel. AH has been on advisory boards for Janssen, Eli Lilly, and Shire. JHN receives or has received research grant support from Enzymotec and Shire. He is also a consultant and/or advisor for Alcobra, Biobehavioral Diagnostics, Ironshore, Neos, NFL, Rhodes, Sunovion, and Shire. VH has received research funding from Shire, Eli Lilly, and Flynn Pharma, and has spoken at educational events sponsored by Shire, Eli Lilly, Janssen Cilag, and Flynn Pharma. VS and BR were employees of Shire at the time of the study.

\section{References}

1. National Institute for Health and Care Excellence. Attention Deficit Hyperactivity Disorder: Diagnosis and Management. Manchester: NICE;2008. Available from: http://www.nice.org.uk/guidance/cg72/ resources/attention-deficit-hyperactivity-disorder-diagnosis-and-management-975625063621. Accessed November 18, 2015.

2. Taylor E, Döpfner M, Sergeant J, et al. European clinical guidelines for hyperkinetic disorder - first upgrade. Eur Child Adolesc Psychiatry. 2004;13 Suppl 1: I7-I30.

3. Michelson D, Allen AJ, Busner J, et al. Once-daily atomoxetine treatment for children and adolescents with attention deficit hyperactivity disorder: a randomized, placebo-controlled study. Am J Psychiatry. 2002; 159:1896-1901.

4. Biederman J, Melmed RD, Patel A, et al. A randomized, double-blind, placebo-controlled study of guanfacine extended release in children and adolescents with attention-deficit/hyperactivity disorder. Pediatrics. 2008;121:e73-e84.

5. Sallee FR, McGough J, Wigal T, Donahue J, Lyne A, Biederman J. Guanfacine extended release in children and adolescents with attentiondeficit/hyperactivity disorder: a placebo-controlled trial. J Am Acad Child Adolesc Psychiatry. 2009;48:155-165.

6. Hodgkins P, Shaw M, Coghill D, Hechtman L. Amfetamine and methylphenidate medications for attention-deficit/hyperactivity disorder: complementary treatment options. Eur Child Adolesc Psychiatry. 2012;21:477-492.

7. Arnsten AF, Jin LE. Guanfacine for the treatment of cognitive disorders: a century of discoveries at Yale. Yale J Biol Med. 2012;85:45-58.

8. Uhlén S, Wikberg JE. Delineation of rat kidney $\alpha 2 \mathrm{~A}$ - and $\alpha 2 \mathrm{~B}$ adrenoceptors with $\left[{ }^{3} \mathrm{H}\right] \mathrm{RX} 821002$ radioligand binding: computer modelling reveals that guanfacine is an $\alpha 2 \mathrm{~A}$-selective compound. Eur J Pharmacol. 1991;202:235-243.

9. Malhotra PA, Parton AD, Greenwood R, Husain M. Noradrenergic modulation of space exploration in visual neglect. Ann Neurol. 2006;59: 186-190.
10. Schulz KP, Clerkin SM, Fan J, Halperin JM, Newcorn JH. Guanfacine modulates the influence of emotional cues on prefrontal cortex activation for cognitive control. Psychopharmacology (Berl). 2013;226:261-271.

11. Singh-Curry V, Malhotra P, Farmer SF, Husain M. Attention deficits following ADEM ameliorated by guanfacine. J Neurol Neurosurg Psychiatry. 2011;82:688-690.

12. Wang M, Ramos BP, Paspalas CD, et al. $\alpha 2 \mathrm{~A}$-adrenoceptors strengthen working memory networks by inhibiting cAMP-HCN channel signaling in prefrontal cortex. Cell. 2007;129:397-410.

13. Wilens TE, Bukstein O, Brams M, et al. A controlled trial of extendedrelease guanfacine and psychostimulants for attention-deficit/ hyperactivity disorder. J Am Acad Child Adolesc Psychiatry. 2012;51: $74-85$.

14. Shire receives European approval for INTUNIV® (guanfacine hydrochloride prolonged release tablets) as a non-stimulant ADHD treatment for children and adolescents [press release]. Shire; 2015 [September 21]. Available from: https://www.shire.com/newsroom/2015/september/nonstimulant-for-adhd-approved-in-europe. Accessed November 30, 2015.

15. Bymaster FP, Katner JS, Nelson DL, et al. Atomoxetine increases extracellular levels of norepinephrine and dopamine in prefrontal cortex of rat: a potential mechanism for efficacy in attention deficit/hyperactivity disorder. Neuropsychopharmacology. 2002;27:699-711.

16. Strattera [summary of product characteristics]. Basingstoke: Eli Lilly and Co; 2015. Available from: http://www.medicines.org.uk/emc/ medicine/14482. Accessed July 30, 2015.

17. Newcorn JH, Kratochvil CJ, Allen AJ, et al. Atomoxetine and osmotically released methylphenidate for the treatment of attention deficit hyperactivity disorder: acute comparison and differential response. Am J Psychiatry. 2008; 165:721-730.

18. Schwartz S, Correll CU. Efficacy and safety of atomoxetine in children and adolescents with attention-deficit/hyperactivity disorder: results from a comprehensive meta-analysis and metaregression. $J$ Am Acad Child Adolesc Psychiatry. 2014;53:174-187.

19. Hervas A, Huss M, Johnson M, et al. Efficacy and safety of extended-release guanfacine hydrochloride in children and adolescents with attention-deficit/hyperactivity disorder: a randomized, controlled, phase III trial. Eur Neuropsychopharmacol. 2014;24: 1861-1872.

20. Newcorn J, Harpin V, Huss M, et al. Extended-release guanfacine hydrochloride in 6-17-year-olds with ADHD: A randomized-withdrawal maintenance of efficacy study. J Child Psychol Psychiatry. Epub 2016 Feb 12.

21. Shire. Maintenance of efficacy of extended-release guanfacine $\mathrm{HCl}$ in children and adolescents with attention-deficit/hyperactivity disorder (ADHD). Available from: https://clinicaltrials.gov/ct2/show/ NCT01081145. NLM identifier: NCT01081145. Accessed November 18, 2015.

22. European Medicines Agency. Guideline on the clinical investigation of medicinal products for the treatment of attention deficit hyperactivity disorder (ADHD). 2010. Available from: http://www.ema.europa. eu/docs/en_GB/document_library/Scientific_guideline/2010/08/ WC500095686.pdf. Accessed July 30, 2015.

23. Berridge CW, Devilbiss DM, Andrzejewski ME, et al. Methylphenidate preferentially increases catecholamine neurotransmission within the prefrontal cortex at low doses that enhance cognitive function. Biol Psychiatry. 2006;60:1111-1120.

24. Easton N, Steward C, Marshall F, Fone K, Marsden C. Effects of amphetamine isomers, methylphenidate and atomoxetine on synaptosomal and synaptic vesicle accumulation and release of dopamine and noradrenaline in vitro in the rat brain. Neuropharmacology. 2007;52: 405-414.

25. Wang GJ, Volkow ND, Wigal T, et al. Long-term stimulant treatment affects brain dopamine transporter level in patients with attention deficit hyperactive disorder. PLoS One. 2013;8:e63023.

26. Fusar-Poli P, Rubia K, Rossi G, Sartori G, Balottin U. Striatal dopamine transporter alterations in ADHD: pathophysiology or adaptation to psychostimulants? A meta-analysis. Am J Psychiatry. 2012;169: 264-272. 
27. Johnson KA, Barry E, Lambert D, et al. Methylphenidate side effect profile is influenced by genetic variation in the attention-deficit/ hyperactivity disorder-associated CES1 gene. J Child Adolesc Psychopharmacol. 2013;23:655-664.

28. Roman T, Rohde LA, Hutz MH. Polymorphisms of the dopamine transporter gene: influence on response to methylphenidate in attention deficit-hyperactivity disorder. Am J Pharmacogenomics. 2004;4:83-92.

29. Coghill DR, Banaschewski T, Lecendreux M, et al. Post hoc analyses of the impact of previous medication on the efficacy of lisdexamfetamine dimesylate in the treatment of attention-deficit/hyperactivity disorder in a randomized, controlled trial. Neuropsychiatr Dis Treat. 2014;10:2039-2047.
30. Dittmann RW, Cardo E, Nagy P, et al. Treatment response and remission in a double-blind, randomized, head-to-head study of lisdexamfetamine dimesylate and atomoxetine in children and adolescents with attentiondeficit hyperactivity disorder. CNS Drugs. 2014;28:1059-1069.

31. Jain R, Babcock T, Burtea T, et al. Efficacy of lisdexamfetamine dimesylate in children with attention-deficit/hyperactivity disorder previously treated with methylphenidate: a post hoc analysis. Child Adolesc Psychiatry Ment Health. 2011;5:35. 


\section{Supplementary materials} Efficacy analysis including prior non-MPH subgroup

A sensitivity analysis of the change in baseline AttentionDeficit/Hyperactivity Disorder Rating Scale version IV (ADHD-RS-IV) total score, including the participants who had reported that their last prior stimulant was a non-methylphenidate (MPH) treatment, is shown in Table S1 for the randomized controlled trial (RCT). As for the comparison between the prior MPH and stimulant-naïve subgroups, nominally significant placebo-adjusted differences in least squares (LS) mean change from baseline to end point on the ADHD-RS-IV were observed in guanfacine extended release (GXR)-treated participants, in both subgroups (any prior stimulant, -10.0 [95\% confidence interval [CI] -14.4 to -5.6$], P<0.001$, effect size $\{\mathrm{ES}\} 0.86$; stimulant-naïve, -7.6 [95\% CI -11.8 to -3.3 ],$P<0.001$, ES 0.66). In atomoxetine (ATX)-treated participants, a nominally significant placebo-adjusted difference in LS mean change from baseline to end point in ADHD-RS-IV was seen in the stimulant-naïve subgroup, but not the prior stimulant subgroup (any prior stimulant, $-2.0[95 \% \mathrm{CI}-6.4$ to 2.3], $P=0.365$, ES 0.17; stimulant-naïve, -5.1 [95\% CI -9.3 to -0.8 ], $P=0.021$, ES 0.44$)$.

A

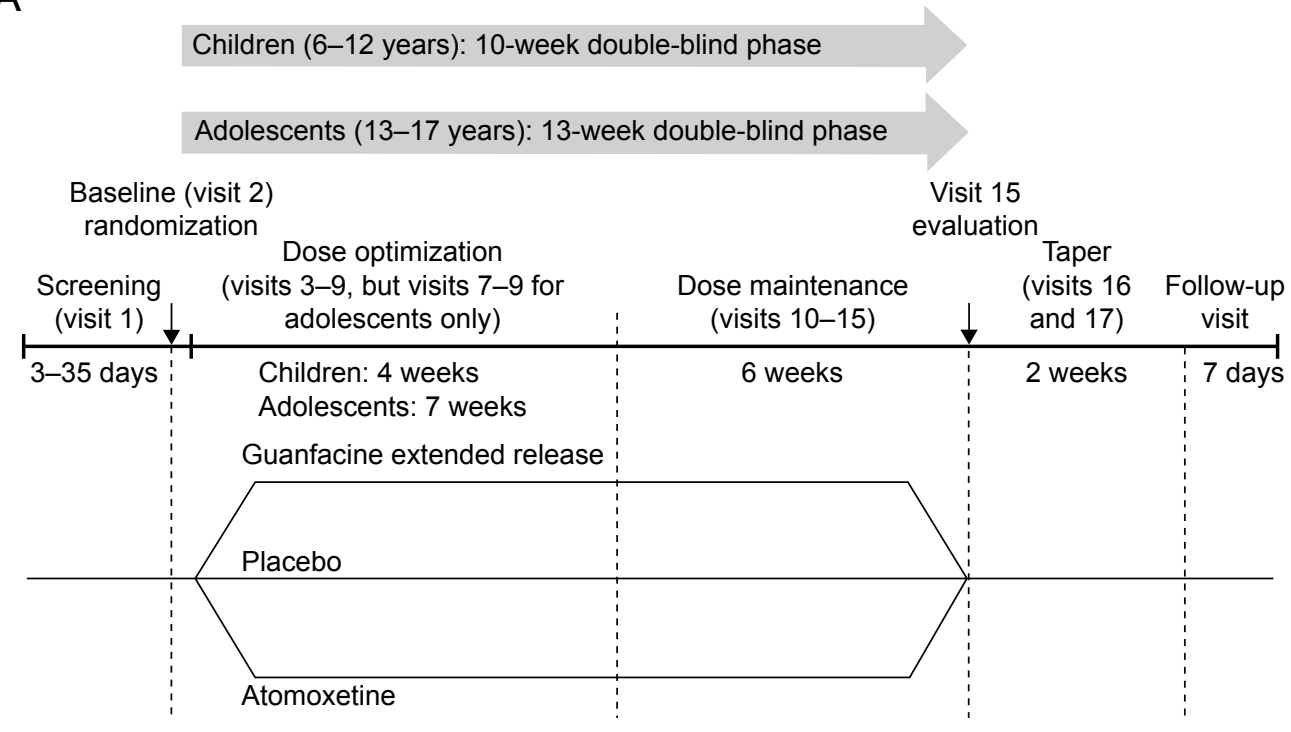

B

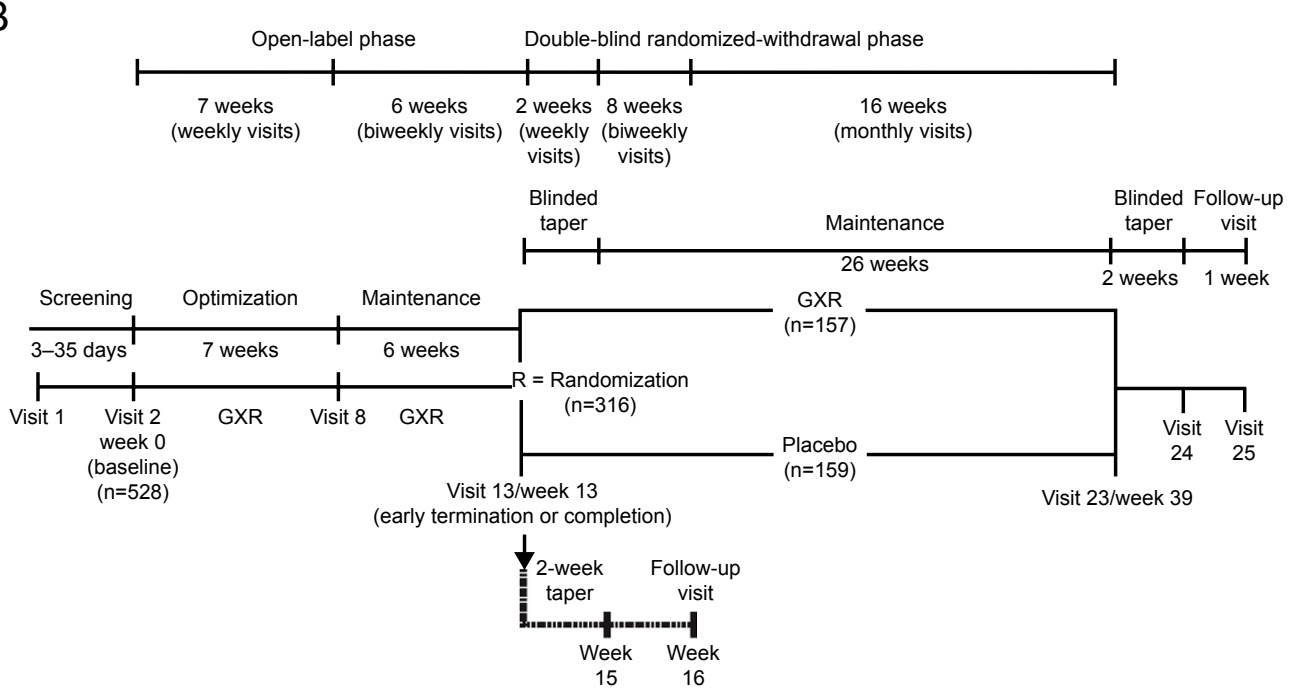

Figure SI Study designs for (A) randomized controlled trial and (B) randomized-withdrawal study.

Note: Only data from the open-label phase were used in this analysis.

Abbreviation: GXR, guanfacine extended release. 
Table SI ANCOVA analysis of change from baseline to end point in ADHD-RS-IV total score by prior stimulant use in the RCT (LOCF; full-analysis set)

\begin{tabular}{|c|c|c|c|c|c|}
\hline $\begin{array}{l}\text { Test vs } \\
\text { comparator }\end{array}$ & $\begin{array}{l}\text { LS mean } \\
(\mathrm{SE})^{*} \\
\text { test }\end{array}$ & $\begin{array}{l}\text { LS mean } \\
(\mathrm{SE})^{*} \\
\text { comparator }\end{array}$ & $\begin{array}{l}\text { Difference in LS mean } \\
\text { treatment - comparator } \\
(95 \% \mathrm{CI})\end{array}$ & $\begin{array}{l}\text { Effect size } \\
(95 \% \mathrm{Cl})\end{array}$ & $P$-value \\
\hline \multicolumn{6}{|c|}{ Any prior stimulant ${ }^{\dagger}$} \\
\hline $\mathrm{GXR}^{\mathrm{a}}$ vs placebob & $\begin{array}{l}-23.283 \\
(1.6703)\end{array}$ & $\begin{array}{l}-13.295 \\
(1.6031)\end{array}$ & $\begin{array}{l}-9.988 \\
(-14.369 \text { to }-5.608)\end{array}$ & $\begin{array}{l}0.86 \\
(0.47 \text { to } I .26)\end{array}$ & $<0.001$ \\
\hline ATX' vs placebo ${ }^{b}$ & $\begin{array}{l}-15.297 \\
(1.6517)\end{array}$ & $\begin{array}{l}-13.295 \\
(1.6031)\end{array}$ & $\begin{array}{l}-2.002 \\
(-6.347 \text { to } 2.344)\end{array}$ & $\begin{array}{l}0.17 \\
(-0.20 \text { to } 0.55)\end{array}$ & 0.365 \\
\hline \multicolumn{6}{|l|}{ Stimulant-naïve } \\
\hline $\mathrm{GXR}^{\mathrm{d}}$ vs placebo ${ }^{\mathrm{e}}$ & $\begin{array}{l}-24.400 \\
(1.5514)\end{array}$ & $\begin{array}{l}-16.835 \\
(1.6211)\end{array}$ & $\begin{array}{l}-7.564 \\
(-11.802 \text { to }-3.327)\end{array}$ & $\begin{array}{l}0.66 \\
(0.28 \text { to } 1.03)\end{array}$ & $<0.001$ \\
\hline ATX $^{f}$ vs placebo ${ }^{e}$ & $\begin{array}{l}-21.887 \\
(1.5784)\end{array}$ & $\begin{array}{l}-16.835 \\
(1.6211)\end{array}$ & $\begin{array}{l}-5.052 \\
(-9.344 \text { to }-0.759)\end{array}$ & $\begin{array}{l}0.44 \\
(0.06 \text { to } 0.81)\end{array}$ & 0.021 \\
\hline
\end{tabular}

Notes: *A negative difference in LS mean (active treatment - placebo) indicates a positive effect of the active treatment over placebo; tincludes both prior MPH and prior non-MPH subgroups. Number of observations per group at visit 15: a $52,{ }^{\circ} 56,{ }^{\circ} 54,{ }^{\mathrm{d}} 60,{ }^{\mathrm{e}} 55$, and ${ }^{\mathrm{f}} 58$.

Abbreviations: ADHD-RS-IV, Attention-Deficit/Hyperactivity Disorder Rating Scale version IV; ANCOVA, analysis of covariance; ATX, atomoxetine; Cl, confidence interval; GXR, guanfacine extended release; LOCF, last observation carried forward; LS, least squares; MPH, methylphenidate; SE, standard error; RCT, randomized controlled trial.

\section{Efficacy analysis by reason for stopping prior MPH treatment}

The efficacy analysis by reason for stopping prior treatment is shown in Table S2. The placebo-adjusted differences in LS mean change from baseline to end point in ADHD-RS-IV total score for those participants who had stopped prior MPH for efficacy reasons $(n=88)$ were nominally significantly different in GXR- and placebo-treated participants $(-10.8[95 \%$ $\mathrm{CI}-18.5$ to -3.2 ], $P=0.006$, ES 0.78), but not in ATX- and placebo-treated participants $(-5.3$ [95\% CI -12.7 to 2.2$]$,
$P=0.161$, ES 0.38). The same pattern and magnitude of response was seen for those participants who had stated safety or tolerability reasons for stopping prior $\mathrm{MPH}$, or for other reasons.

\section{Time to response}

Time to response for the $\geq 50 \%$ reduction from baseline in ADHD-RS-IV total score was nominally significantly different from placebo in GXR-treated participants in both subgroups (median [95\% CI] time: prior $\mathrm{MPH}$,

Table S2 ANCOVA analysis of change from baseline to end point in ADHD-RS-IV total score by reason for stopping prior MPH treatment (LOCF; full-analysis set)

\begin{tabular}{|c|c|c|c|c|c|}
\hline $\begin{array}{l}\text { Test vs } \\
\text { comparator }\end{array}$ & $\begin{array}{l}\text { LS mean } \\
(\mathrm{SE})^{*} \\
\text { test }\end{array}$ & $\begin{array}{l}\text { LS mean } \\
(\mathrm{SE})^{*} \\
\text { comparator }\end{array}$ & $\begin{array}{l}\text { Difference in LS mean } \\
\text { treatment - comparator } \\
(95 \% \mathrm{Cl})\end{array}$ & $\begin{array}{l}\text { Effect size } \\
(95 \% \mathrm{Cl})\end{array}$ & $P$-value \\
\hline \multicolumn{6}{|c|}{ Combined efficacy failure } \\
\hline $\mathrm{GXR}^{\mathrm{a}}$ vs placebob & $\begin{array}{l}-22.929 \\
(3.9409)\end{array}$ & $\begin{array}{l}-12.113 \\
(3.4445)\end{array}$ & $\begin{array}{l}-10.817 \\
(-18.480 \text { to }-3.154)\end{array}$ & $\begin{array}{l}0.78 \\
(0.22 \text { to } 1.35)\end{array}$ & 0.006 \\
\hline ATX $^{\mathrm{c}}$ vs placebo ${ }^{\mathrm{b}}$ & $\begin{array}{l}-17.405 \\
(3.7057)\end{array}$ & $\begin{array}{l}-12.113 \\
(3.4445)\end{array}$ & $\begin{array}{l}-5.292 \\
(-12.735 \text { to } 2.150)\end{array}$ & $\begin{array}{l}0.38 \\
(-0.15 \text { to } 0.92)\end{array}$ & 0.161 \\
\hline \multicolumn{6}{|c|}{ Safety/tolerability } \\
\hline $\mathrm{GXR}^{\mathrm{d}}$ vs placebo ${ }^{\mathrm{e}}$ & $\begin{array}{l}-23.770 \\
(4.1920)\end{array}$ & $\begin{array}{l}-12.818 \\
(3.6314)\end{array}$ & $\begin{array}{l}-10.952 \\
(-21.115 \text { to }-0.789)\end{array}$ & $\begin{array}{l}0.73 \\
(0.05 \text { to } 1.42)\end{array}$ & 0.035 \\
\hline ATX $^{d}$ vs placebo ${ }^{e}$ & $\begin{array}{l}-18.242 \\
(4.1288)\end{array}$ & $\begin{array}{l}-12.818 \\
(3.6314)\end{array}$ & $\begin{array}{l}-5.425 \\
(-15.720 \text { to } 4.87 I)\end{array}$ & $\begin{array}{l}0.36 \\
(-0.3 \mid \text { to } 1.03)\end{array}$ & 0.295 \\
\hline \multicolumn{6}{|c|}{ Other reasons (excluding inability to pay for medication) } \\
\hline GXR $^{e}$ vs placebof & $\begin{array}{l}-38.148 \\
(4.5166)\end{array}$ & $\begin{array}{l}-22.345 \\
(4.0536)\end{array}$ & $\begin{array}{l}-15.803 \\
(-24.870 \text { to }-6.735)\end{array}$ & $\begin{array}{l}1.12 \\
(0.44 \text { to } 1.80)\end{array}$ & $<0.001$ \\
\hline ATX $^{g}$ vs placebo ${ }^{f}$ & $\begin{array}{l}-23.179 \\
(4.3409)\end{array}$ & $\begin{array}{l}-22.345 \\
(4.0536)\end{array}$ & $\begin{array}{l}-0.834 \\
(-10.158 \text { to } 8.49 \mid)\end{array}$ & $\begin{array}{l}0.06 \\
(-0.56 \text { to } 0.68)\end{array}$ & 0.859 \\
\hline
\end{tabular}

Notes: *A negative difference in LS mean (active treatment - placebo) indicates a positive effect of the active treatment over placebo. Number of observations per group at visit 15: ${ }^{2} 24,{ }^{\circ} 28,{ }^{c} 27,{ }^{\mathrm{d}} 17, \mathrm{e} 18,{ }^{\mathrm{f}} 21$, and $\mathrm{g} \mid 9$. Reasons not mutually exclusive.

Abbreviations: ADHD-RS-IV, Attention-Deficit/Hyperactivity Disorder Rating Scale version IV; ANCOVA, analysis of covariance; ATX, atomoxetine; CI, confidence interval; GXR, guanfacine extended release; LOCF, last observation carried forward; LS, least squares; MPH, methylphenidate; SE, standard error. 

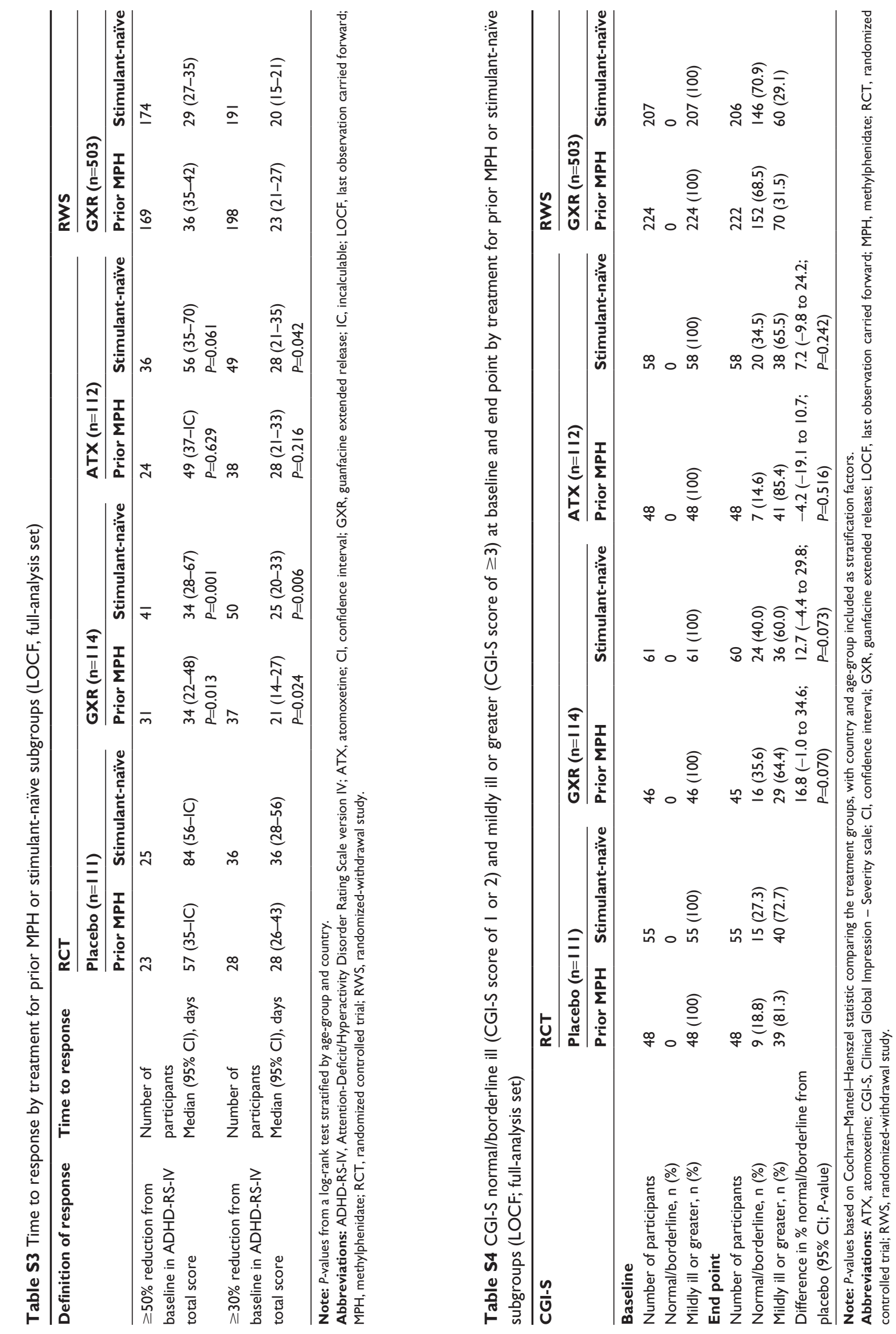
Table S5 Combined responder analyses at end point for the RCT (ad hoc analyses; LOCF, full-analysis set)

\begin{tabular}{|c|c|c|c|c|}
\hline Definition of response & Response & Placebo $(n=I \mid I)$ & GXR (n=I|4) & $\operatorname{ATX}(n=|| 2)$ \\
\hline$\geq 30 \%$ reduction from & Number of participants & 111 & 112 & 112 \\
\hline baseline in ADHD-RS-IV & Responders, n (\%) & $47(42.3)$ & $72(64.3)$ & $62(55.4)$ \\
\hline and $\mathrm{CGI}-\mathrm{I}$ score of I or 2 & $\begin{array}{l}\text { Difference in \% responders from placebo } \\
(95 \% \mathrm{Cl} ; P \text {-value) }\end{array}$ & & $\begin{array}{l}21.9 \\
(9.2-34.7 ; P<0.001)\end{array}$ & $\begin{array}{l}13.0 \\
(0-26.0 ; P=0.017)\end{array}$ \\
\hline$\geq 50 \%$ reduction from & Number of participants & III & 112 & 112 \\
\hline baseline in ADHD-RS-IV & Responders, n (\%) & $33(29.7)$ & $60(53.6)$ & $47(42.0)$ \\
\hline and CGI-I score of I or 2 & $\begin{array}{l}\text { Difference in \% responders from placebo } \\
(95 \% \mathrm{Cl} ; \mathrm{P} \text {-value })\end{array}$ & & $\begin{array}{l}23.8 \\
(11.3-36.4 ; P<0.001)\end{array}$ & $\begin{array}{l}12.2 \\
(-0.2 \text { to } 24.7 ; P=0.018)\end{array}$ \\
\hline
\end{tabular}

Abbreviations: ADHD-RS-IV, Attention-Deficit/Hyperactivity Disorder Rating Scale version IV; ATX, atomoxetine; CGI-I, Clinical Global Impression - Improvement scale; $\mathrm{Cl}$, confidence interval; GXR, guanfacine extended release; LOCF, last observation carried forward; RCT, randomized controlled trial.

34 [22-48] days, $P=0.013$; stimulant-naïve, 34 [28-67] days, $P=0.001)$. However, it was not nominally significant in either subgroup among ATX-treated participants (median $[95 \%$ $\mathrm{CI}]$ time: prior MPH, 49 [37 to incalculable] days, $P=0.629$; stimulant-naïve, 56 [35-70] days, $P=0.061$; Table S3). The time to response with GXR, as defined by a $\geq 30 \%$ reduction from baseline in ADHD-RS-IV total score response, followed the same significance pattern (median [95\% CI] time: prior $\mathrm{MPH}, 21$ [14-27] days, $P=0.024$; stimulantnaïve, 25 [20-33] days, $P=0.006)$. However, ATX-treated participants differed slightly, as a nominally significantly shorter time to response than placebo was achieved for the stimulant-naïve subgroup, but not the prior MPH subgroup (median [95\% CI] time: prior MPH, 28 [21-33] days, $P=0.216$; stimulant-naïve, 28 [21-35] days, $P=0.042)$. The time to response was similar in GXR-treated participants in both the prior MPH and stimulant-naïve subgroups in the open-label phase of the randomized-withdrawal study for both the $\geq 50 \%$ threshold (median [95\% CI] time: prior MPH, 36 [35-42] days; stimulant-naïve, 29 [27-35] days) and the $\geq 30 \%$ threshold (median [95\% CI] time: prior $\mathrm{MPH}$, 23 [21-27] days; stimulant-naïve, 20 [15-21] days).
Neuropsychiatric Disease and Treatment

\section{Publish your work in this journal}

Neuropsychiatric Disease and Treatment is an international, peerreviewed journal of clinical therapeutics and pharmacology focusing on concise rapid reporting of clinical or pre-clinical studies on a range of neuropsychiatric and neurological disorders. This journal is indexed on PubMed Central, the 'PsycINFO' database and CAS,

\section{Dovepress}

and is the official journal of The International Neuropsychiatric Association (INA). The manuscript management system is completely online and includes a very quick and fair peer-review system, which is all easy to use. Visit http://www.dovepress.com/testimonials.php to read real quotes from published authors. 